\title{
Identifying Awareness, Use, and Perceptions of text4baby among Family Medicine and Obstetrics and Gynecology Practitioners at the University of
} Kansas Medical Center

\author{
Brent Bjornsen, MS4 ${ }^{1}$, Mark McHaney, MS4 ${ }^{1}$, Katie Merando, MS4 ${ }^{1}$, Cameron Tusken, MS4 ${ }^{1}$, \\ Christie Befort, Ph.D. ${ }^{2}$, Cristi Cain, M.P.H. ${ }^{3}$, Pam Shaw, M.D. ${ }^{4}$ \\ ${ }^{1}$ University of Kansas School of Medicine, Kansas City, KS \\ ${ }^{2}$ University of Kansas School of Medicine, Kansas City, KS \\ Department of Preventive Medicine and Public Health \\ ${ }^{3}$ Kansas Department of Health and Environment, Topeka, KS \\ ${ }^{4}$ University of Kansas School of Medicine, Kansas City, KS, Department of Pediatrics
}

\begin{abstract}
Background. Low income minority women who receive inadequate or no prenatal care have greater infant morbidity and mortality in the postnatal period. Mobile health or mHealth initiatives such as text4baby are presumed to be a means to reach underserved pregnant and postpartum women to increase their use of prenatal and postnatal care. Providers are an important referral source for mHealth initiatives. It is important, therefore, to assess the awareness, use, and perceptions of the text4baby program among Family Medicine and Obstetrics/Gynecology (Ob/Gyn) providers to determine the means to increase referrals and improve outcomes for pregnant mothers and infants.
\end{abstract}

Methods. Family medicine and Ob/Gyn providers (attending physicians, residents, nurse practitioners, nurses, and medical assistants) at the University of Kansas Medical Center (KUMC) completed a survey assessing awareness of use and perceived utility of text4baby as well as experience with technology and reservations about mHealth in general.

Results. Seventy-eight providers (38 in Family Medicine and 40 in Ob/Gyn) responded to the survey. Awareness of text4baby among all providers was 18\%. Among the 14 providers who knew about text4baby, one individual stated he/she regularly refers patients to text4baby and 11 agreed that text4baby is a useful tool for the care of pregnant patients. Comparison of text4baby awareness by demographic factors showed no significant differences between any of the groups. Providers who knew of mHealth applications were more likely to know about text4baby $(\mathrm{p}=$ 0.04). Older providers were less likely to have reservations about using mHealth in their practice $(p=0.02)$. There was widespread agreement $(87 \%)$ that providing evidence to clinicians that text4baby improves outcomes would increase use of the service in clinical practice.

Conclusions. Awareness of text4baby among practitioners at KUMC is minimal; use is negligible. Our study identified lack of awareness of the text4baby service and of supporting evidence about its effectiveness as the primary barriers to referral.

KS J Med 2014; 7(4):132-138.

\section{Introduction}

Low income minority women who receive inadequate or no prenatal care have greater infant morbidity and mortality in the postnatal period. ${ }^{1}$ These women often do not receive prenatal screening or education about their pregnancy, which would improve the health outcomes of newborns. ${ }^{2-5}$ These women also have lower levels of attendance at maternal postnatal visits, well-child visits, immunization completions, and acute care visits. ${ }^{1}$ One potential way to improve uptake of prenatal care and the health outcomes of these women is through the use of a mobile health (mHealth) system such as text4baby. 
mHealth initiatives such as text4baby are an important means by which to reach underserved pregnant and postpartum women, as long as the enrollment process is as simple as possible. ${ }^{6}$ text4baby (https:// www.text4baby.org) sends up to 267 messages to pregnant women and mothers of newborns, containing a breadth of information including prenatal health habits, signs and symptoms of labor, when to seek the expert counsel of a physician, and appointment reminders. This is done based on the mother-to-be's due date to provide information appropriate for her gestational milestones.

The potential impact of text4baby is due in part because $90 \%$ of women in the US have cell phones and texting is more prevalent among women of childbearing age and minority groups. ${ }^{7}$ Additionally, as much as $96 \%$ of pregnant women are interested in receiving text messages regarding prenatal care. ${ }^{8}$ Educating these pregnant women through text4baby may increase prenatal care utilization, thus pregnancy outcomes and postnatal care utilization. ${ }^{1}$ In preliminary studies, text4baby and similar text message services have improved the health of mothers. Mothers receiving text4baby have better glucose control and report being more satisfied with their prenatal care, having higher confidence, and being less anxious about their pregnancy compared to mothers in a control group. 9,10

Current evidence supports the use of text messaging as a tool for behavior change. ${ }^{11}$ However, the first step in the success of text4baby is increasing its utilization by patients. Advertisements to encourage enrollment in the program range from billboards to magazine spreads. Physicians are an important expert opinion for patients, especially regarding new mobile services such as text4baby. There is, potentially, a lack of knowledge among health care providers regarding the text4baby program which may reduce its reach and effectiveness. In 2013, the Kansas Department of Health and Environment awarded mini-grants to 32 programs serving 54 total counties to increase awareness of the service among pregnant women. However, while there was one program targeting Kansas City, KS, it utilized the funds in conjunction with movie theaters in the far western area of the county for direct marketing to pregnant women. ${ }^{12}$ This represented only a minority of the population of Wyandotte County and did not target awareness among medical providers.

U.S. News and World Report named the University of Kansas Hospital as the leading center for women's health in the region, and there are over 40,000 visits to the $\mathrm{Ob} / \mathrm{Gyn}$ clinics each year. ${ }^{13}$ Patient visits to Family Medicine clinics at the University of Kansas Hospital totaled 28,477 in 2013. There exists a vast opportunity for mHealth to provide an efficient means by which to affect patient care. Because providers can play a key role in mHealth effectiveness by referring to and reinforcing the intervention messages, it is important to assess their awareness, use, and perceptions of the service. This study surveyed the University of Kansas Family Medicine and $\mathrm{Ob} / \mathrm{Gyn}$ practitioners to assess current awareness and determine any means by which to improve text4baby utilization.

\section{Methods}

Participants and setting. Survey respondents were members of the KUMC Family Medicine and Ob/Gyn departments, including faculty, residents, nurse practitioners, physician assistants, nurses, and medical assistants. A REDCap ${ }^{\mathrm{TM}}$ survey was created and distributed via email to identified providers, as well as in person at the Family Medicine clinic and resident conferences for both specialties.

Measures. Survey domains assessed knowledge of the text4baby program 
(awareness), referral of text4baby program to patients (use), and perceived usefulness of and barriers to the text4baby program (including patient compliance, health and technological literacy, and privacy issues). Additional variables included field of practice, practitioner role, age, gender, frequency of seeing pregnant patients, personal and professional text message use, awareness and use of mHealth, patients asking about mHealth, reservations about mHealth, and willingness to adopt text4baby if provided evidence it improved outcomes.

Sample size justification. A total of 135 individuals were identified as providers in the Family Medicine and Ob/Gyn departments. A sample size of 43 would provide a $95 \%$ confidence interval of $\pm 10 \%$ around our estimated current awareness of $20 \%$.

Statistical analysis. Univariate statistics were used to describe variables. Chi-square analyses were used to examine correlates of awareness, use, and perception of text4baby among practitioners.

\section{Results}

One-hundred thirty-five surveys were distributed and a total of 78 providers responded (58\% response rate, 38 Family Medicine and 40 Ob/Gyn providers). Respondent characteristics, mobile use, and mHealth reservations are described in Table 1. Among questions identifying mobile use, $92 \%(\mathrm{n}=72)$ of respondents reported texting for personal use compared to $50 \%$ (n = 39) who text for professional use and $47 \%$ ( $n=37$ ) who use mobile devices to access patient health information. Only 8\% $(n=6)$ indicated that patients regularly ask them about mHealth applications.

Eighteen percent $(n=14)$ of respondents were aware of the text4baby program (see Table 2). Among these providers who were aware, one individual stated he/she regularly refers patients to text4baby $(1.6 \%$ of the total sample), 11 (79\%) agreed that they believe text4baby is a useful tool for the care of pregnant patients, and 10 (72\%) indicated

Table 1. Provider characteristics $(n=78)$.

\begin{tabular}{|c|c|c|}
\hline Characteristic & $\mathbf{n}$ & $\%$ \\
\hline \multicolumn{3}{|l|}{ Field Of Practice } \\
\hline Family Medicine & 38 & $48.7 \%$ \\
\hline Ob/Gyn & 40 & $51.3 \%$ \\
\hline \multicolumn{3}{|l|}{ Practitioner Role } \\
\hline Attending Physician & 30 & $38.5 \%$ \\
\hline Resident & 24 & $30.8 \%$ \\
\hline Nurse Practitioner & 3 & $3.9 \%$ \\
\hline Registered Nurse & 20 & $25.6 \%$ \\
\hline Medical Assistant & 1 & $1.3 \%$ \\
\hline \multicolumn{3}{|l|}{ Age } \\
\hline $18-35$ & 41 & $52.6 \%$ \\
\hline $36-55$ & 28 & $35.9 \%$ \\
\hline$>55$ & 9 & $11.5 \%$ \\
\hline \multicolumn{3}{|l|}{ Gender } \\
\hline Male & 15 & $19.2 \%$ \\
\hline Female & 63 & $80.8 \%$ \\
\hline $\begin{array}{l}\text { Regularly see pregnan } \\
\text { patients in practice }\end{array}$ & 59 & $75.6 \%$ \\
\hline \multicolumn{3}{|c|}{ Mobile Knowledge/Habits } \\
\hline $\begin{array}{l}\text { Regularly text for } \\
\text { personal use }\end{array}$ & 72 & $92.3 \%$ \\
\hline $\begin{array}{l}\text { Regularly text for } \\
\text { professional use }\end{array}$ & 39 & $50.0 \%$ \\
\hline $\begin{array}{l}\text { Aware of mHealth } \\
\text { applications for patien } \\
\text { care }\end{array}$ & 42 & $53.9 \%$ \\
\hline $\begin{array}{l}\text { Regularly asked by } \\
\text { patients about mHealt } \\
\text { applications }\end{array}$ & 6 & $7.7 \%$ \\
\hline $\begin{array}{l}\text { Regularly use mobile } \\
\text { device to access } \\
\text { patient health }\end{array}$ & & \\
\hline information & 37 & $47.4 \%$ \\
\hline
\end{tabular}

if they were to refer, socioeconomic status, age, and insurance status of the patient would not play a role in their decision to refer $(90 \%, 80 \%$, and $100 \%$ respectively 
said that these issues do not play a factor).

Thirty-nine percent $(n=30)$ of providers stated they have no reservations to using mobile health applications in their regular practice (see Table 2). Of the remaining $61 \%(n=48)$, a variety of barriers were endorsed including patient health literacy, program efficacy, compliance concerns, and patient privacy. Eighty-seven percent $(\mathrm{n}=$ 68) of respondents agreed that if evidence was provided regarding text4baby efficacy for improving health outcomes for pregnant patients and their infants, they would be likely to incorporate the program into their regular practice.

Table 2. Awareness and use of text4baby and reservations to mHealth ( $\mathrm{n}=78)$.

\begin{tabular}{|llc|}
\hline Variable & $\mathbf{n}$ & $\mathbf{\%}$ \\
Aware of text4baby & 14 & $18.0 \%$ \\
Regularly refer patients to text4baby & 1 & - \\
Believe text4baby is a useful tool & 11 & - \\
Likely to refer to text4baby provided evidence supporting & & $87.2 \%$ \\
improved outcomes & 68 & \\
Reservations about mHealth & & $11.5 \%$ \\
$\quad$ Patient Privacy & & $14.1 \%$ \\
$\quad$ Patient Compliance & 9 & $10.2 \%$ \\
Time Concerns & 11 & $7.7 \%$ \\
Patients Do Not Have Resources to Make Change & 8 & $11.5 \%$ \\
Patient Tech Literacy & 6 & $23.1 \%$ \\
Patient Health Literacy & 9 & $15.4 \%$ \\
Program Efficacy Concerns & 18 & $9.0 \%$ \\
Patient Education Material Availability & 12 & $38.5 \%$ \\
No Reservations & 7 & \\
\hline
\end{tabular}

Comparison of the awareness of text4baby by demographic factors (specialty, role in patient care, age, and sex) showed no significant difference between any of the groups. Providers who were aware of other mHealth applications also were more likely to be aware of text4baby (p $=0.04)$. Physicians were more likely to be willing to refer to text4baby than nonphysician providers $(p=0.03)$. Providers age 18-34 and 35-54 were more likely to have reservations about using mHealth applications compared to providers over the age of $55(\mathrm{p}=0.02)$. Providers who regularly see pregnant patients also had more reservations about using mHealth compared to providers who do not routinely see pregnant patients $(p=0.05)$.

\section{Discussion}

Text4baby is a growing mHealth initiative that shows promise in practitioners' ability to provide supplemental important health information to pregnant patients outside of the practice setting. To date, over 650,000 individuals 
have signed up for the program, a number which continues to rise. ${ }^{14}$ However, many women who would benefit from this program may not be aware of its existence, due to both a lack of provider awareness and marketing issues.

The World Health Organization reported that there is a lack of knowledge concerning the possible applications of mHealth, both among providers and non-providers; this exemplifies the ongoing need to keep providers informed of trends and developments in the field, and communicate mHealth research findings and evaluations within the broader context of patient care. ${ }^{15}$

This knowledge gap is being addressed on a larger scale in various projects and studies across the world; however, there is room for a hyper-local lens to examine the use and efficacy of mHealth in Kansas. Our goal was to assess the awareness, use, and perceptions of the text4baby program among Family Medicine and Ob/Gyn providers.

Awareness of text4baby was minimal at KUMC, and only one provider said he/she regularly refers patients to the program. Providers' field of practice, age, gender, or role did not correlate with awareness of the program. There also was no difference in awareness of text4baby between providers who used other mHealth applications in their practice and those who did not. This may, perhaps, point to a lack of direct marketing to providers about the text4baby service rather than an unwillingness of providers to use the service per se.

Providers' mobile device use was much higher for personal than for professional use, with only half of them regularly texting and using mobile devices for professional use. Surprisingly, providers over the age of 55 were less likely to have reservations regarding the use of mHealth applications. The reason for this is unclear. Perhaps younger generations have a more inherent conscience of the barriers and failures of technology. Additionally, providers who regularly see pregnant patients in their practice were more likely to have reservations about using mHealth compared to those who never/rarely do. Further study is needed to explore the reasons behind provider perceptions regarding mHealth applications. Regardless, many of the reservations and barriers that we identified are echoed in larger studies about mHealth. The World Health Organization commented in its second annual survey about eHealth:

Many of the top six barriers to mHealth implementation are related to the need for further knowledge and information, such as assessing effectiveness and cost-effectiveness of mHealth applications. Other key barriers included conflicting health system priorities, the lack of supporting policy, and legal issues. ${ }^{15}$

Additional study, especially in Kansas, should be directed at identifying beliefs behind these barriers and methods of minimizing their impact upon the using of mHealth.

Very few providers indicated that they are regularly asked by patients about mHealth services. Providers likely would not know if their patients are using such programs as patients often do not report where they receive other health information. With providers being unaware of common mHealth services being marketed to patients, there is a potential lost opportunity for them to address important patient health information needs. Perhaps, the most important finding of this study was that the majority of providers likely would utilize text4baby if evidence was provided to them that it improved outcomes. Seminars, webinars, or other methods could provide avenues by which providers can learn about tools like text4baby and their usefulness in their regular practice. 


\section{Conclusion}

Awareness of text4baby among practitioners at KUMC is minimal and its use is negligible. Our study identified this issue and attempted to elicit the perceptions that play into this reality. It remains a program which has a strong potential to provide quality care to pregnant patients and improve outcomes. With this in mind,

\section{References}

${ }^{1}$ York R, Tulman L, Brown K. Postnatal care in low-income urban African American women: Relationship to level of prenatal care sought. J Perinatol 2000; 20(1):34-40. PMID: 10693098.

2 Crowther CA, Hiller JE, Moss JR, et al. Effect of treatment of gestational diabetes mellitus on pregnancy outcomes. N Engl J Med 2005; 352(24):2477-2486. PMID: 1595174.

${ }^{3}$ Gilson GJ, Christensen F, Romero H, Bekes K, Silva L, Qualls CR. Prevention of group B streptococcus early-onset neonatal sepsis: Comparison of the Center for Disease Control and Prevention screening-based protocol to a risk-based protocol in infants at greater than 37 weeks' gestation. J Perinatol 2000; 20(8 Pt 1):491-495. PMID: 11190588.

${ }^{4}$ Wilson RD, Davies G, Désilets V, et al. The use of folic acid for the prevention of neural tube defects and other congenital anomalies. J Obstet Gynaecol Can 2003; 25(11):959-973. PMID: 14608448.

${ }^{5}$ Chung M, Raman G, Trikalinos T, Lau J, Ip S. Interventions in primary care to promote breastfeeding: An evidence review for the U.S. Preventive Services Task Force. Ann Intern Med 2008; 149(8):565-582. PMID: 18936504.

${ }^{6}$ Gazmararian JA, Elon L, Yang B, Graham M, Parker R. Text4baby program: An opportunity to reach underserved pregnant and postpartum women? Matern Child Health J 2014; 18(1):223-332. PMID: further studies and initiatives are needed to identify reasons for incorporating such a program into practice and perceptions of mHealth in general. Furthermore, additional studies are needed to examine the efficacy of the program and to improve its uptake by the targeted low socioeconomic pregnant population.

\section{5.}

7 Jordan ET, Ray EM, Johnson P, Evans WD. Text4Baby: Using text messaging to improve maternal and newborn health. Nurs Womens Health 2011; 15(3):206212. PMID: 21672170.

${ }^{8}$ Cormick G, Kim NA, Rodgers A, et al. Interest of pregnant women in the use of SMS (short message service) text messages for the improvement of perinatal and postnatal care. Reprod Health 2012; 9:9. PMID: 22866753.

${ }^{9}$ Grabosch S, Gavard JA, Mostello D. Text4baby improves glycemic control in pregnant women with diabetes. [Abstract]. Am J Obstet Gynecol 2014; 210(1):S88.

${ }^{10}$ Jareethum R, Titapant V, Chantra T, Sommai V, Chuenwattana P, Jirawan C. Satisfaction of healthy pregnant women receiving short message service via mobile phone for prenatal support: A randomized controlled trial. J Med Assoc Thai 2008; 91(4):458-463. PMID: 18556852.

${ }^{11}$ Cole-Lewis H, Kershaw T. Text messaging as a tool for behavior change in disease prevention and management. Epidemiol Rev 2010; 32(1):56-69. PMID: 20354039.

12 text4baby.org. Text4baby - State Partner Spotlights. Text4baby - Minigrants Significantly Increased Enrollment in Kansas! Available at: https:// text4baby.org/index. php/get-involved-pg/partners/stateorganiz ations/2-uncategorised/97. January 14, 2014. Accessed February 4, 2014. 
${ }^{13}$ University of Kansas Medical Center. Shining Through: Department of Obstetrics and Gynecology 2012 Annual Report. Available at: http://www.kumc. edu/Documents/obgyn/AR2012. Accessed March 5, 2014.

${ }^{14}$ text4baby.org. text4baby Enrollment Data. Available at: https://text4baby.org/index. php/get-involved-pg/partners/national-org anization/7-partner-resources/105.

Accessed March 5, 2014.
${ }^{15}$ World Health Organization. MHealth: New Horizons for Health through Mobile Technologies. World Health Organization; 2011. Available at: http://www.who.int/ goe/publications/goe_mhealth_web.pdf. Accessed May 23, 2014.

Keywords: mobile applications, text messaging, prenatal care, pregnancy 